\title{
Spawning and non-breeding activity of adult giant bullfrogs (Pyxicephalus adspersus)
}

\author{
Caroline A. Yetman \& J. Willem H. Ferguson \\ Department of Zoology and Entomology, University of Pretoria, Pretoria, South Africa
}


Abstract.-Populations of the Near-Threatened giant bullfrog (Pyxicephalus adspersus) have been poorly monitored due to the unpredictable appearance of this species aboveground. To better understand the activity of $P$. adspersus we quantified spawning by a population during five summers, and the activity of twenty adult frogs radio-tracked at the same site ca. twice weekly during the first three summers. In addition we examined animal activity, and population spawning in relation to meteorological variables, day of season, and moon light. During the six-month summer period, males and females, respectively, spent $10 \pm 7$ and $3 \pm 2$ days at water, and $22 \pm 5$ and $13 \pm 5$ nights active. Greater proportions of radio-tracked animals moved overland, and/or foraged at night, around full moon, after heavy rainfall, when cooler, and less windy conditions prevailed. More animals were found at water, or on land during the day, and population spawning was more likely, earlier in summer, following heavier rainfall. Spawning occurred most frequently, in descending order, during December, January, and November, and was triggered by $40 \pm 16$ $\mathrm{mm}$ rain in $24 \mathrm{~h}$. Spawning events lasted $2 \pm 1$ days, but were prolonged around full moon. Numbers of males at spawning events varied between 30 and 500 males, and were positively correlated with the previous day's rainfall. Annually $6 \pm 1$ spawning events occurred, and numbers of annual spawning events were positively correlated with total summer rainfall. Results of this study show that single counts of spawning adults will often result in gross underestimates of population size, and therefore, long-term adult counts are necessary to detect real population trends. Due to the unpredictable activity of adults, however, it may be more practical to monitor, within certain areas, the number of aquatic sites where breeding occurs, for improved conservation management of $P$. adspersus. 
Although photoperiod and the lunar cycle provide predictable cues that amphibians may use to synchronize their behaviour (Fitzgerald \& Bider 1974; Both et al. 2008; Canavero \& Arim 2009; Grant et al. 2009), the activity of many species is ultimately dictated by unpredictable climatic variables because of their permeable skin and ectothermic bodies (Duellman \& Trueb 1994). Among these, precipitation tends to exert the greatest influence (Bulger et al. 2003; Lemckert \& Brassil 2003), but temperature (Howard 1978; Van Gelder et al. 1986), humidity (Bellis 1965; Bartelt et al. 2004), wind (Penman et al. 2006; Philips et al. 2007), light intensity/cloud cover (Jameson 1955; Blankenhorn 1972), and barometric pressure (Blankenhorn 1972) can also significantly affect amphibian activity. Amphibians in dry and/or cold environments are most limited by suitable warm, wet conditions, making it difficult to predict their behaviour or even their presence (e.g., Bulger et al. 2003; Bartelt et al. 2004; Goldberg \& Schwalbe 2004). This can represent a serious challenge for effective conservation management of threatened amphibian taxa (e.g., Penman et al. 2006).

Giant bullfrogs (Pyxicephalus adspersus) are large frogs (males: 400-1 $000 \mathrm{~g}$; females: 90-300 g; Cook 1996) inhabiting arid to subtropical grassland and savannah in southern Africa (Channing 2001). Individuals remain underground in a state of torpor except in summer when triggered by heavy rain to spawn explosively in shallow, ephemeral water bodies (Balinsky \& Balinsky 1954; Grobler 1972). Little is known about the non-breeding biology of this species apart from its diet, and burrowing physiology (Loveridge \& Withers 1981; Van Aardt 1992; Du Preez \& Cook 2004; Secor 2005). Currently, P. adspersus is listed as Near-Threatened in South Africa (Minter et al. 2004; IUCN 2008), where habitat 
loss and other factors have led to local population declines of $50-80 \%$, particularly in Gauteng Province (Harrison et al. 2001). Unfortunately, due to the highly unpredictable activity of $P$. adspersus, the species has been subject to limited field-based research and monitoring (Jacobsen 1989; Kok et al. 1989; Van Wyk et al. 1992; Cook 1996). This has hindered accurate assessment of the size, and breeding success, of important historical populations (e.g., at Glen Austin and Bullfrog pans near Johannesburg). The resulting lack of demographic information for the species has impeded assessment of its conservation status, and provides a weak baseline for evaluation of efforts to protect threatened populations.

In the present study we aimed to examine the spawning and non-breeding activity of adult P. adspersus in relation to meteorological variables, to contribute towards improved detection, monitoring, and conservation management of this species. Specific objectives of the study were to:

1) Quantify the annual spawning, and non-breeding activity of adult $P$. adspersus.

2) Determine whether males and females exhibit different patterns of diurnal or nocturnal activity.

3) Examine the diurnal, nocturnal, and spawning activity of adult $P$. adspersus in relation to meteorological variables, day of season, and moon light.

4) Infer consequences of the results on the conservation management of $P$. adspersus.

\section{MATERials AND Methods}


Study site.-The study site was located in Diepsloot, Gauteng Province, South Africa (2528CC: $25^{\circ} 56^{\prime} 23.59^{\prime \prime} \mathrm{S}, 28^{\circ} 01^{\prime} 21.88^{\prime \prime} \mathrm{E} ; 1427-72 \mathrm{~m}$ a.s.1.), and comprised $\sim 100$ ha of degraded Egoli Granite Grassland (Mucina et al. 2005). Local bullfrogs bred in three small ( 0.2-0.9 ha), shallow ( $<2$ m deep), human-created, seasonal dams (named Dams 1, 2 and 3), situated in the southern section of the site. The site is representative of many areas where $P$. adspersus faces encroaching urbanization on remaining fragments of undeveloped habitat. We collected data on P. adspersus at the site between 1 October and 31 March in the seasons 2003/2004, 2004/2005, 2005/2006, 2006/2007, and 2007/2008 - hereafter referred to as Summers 1-5.

Radio-tracking.- In Summers 1-3, we haphazardly selected 10 males and 20 females for radio-tracking from adult $P$. adspersus caught for a separate mark-recapture study. We captured frogs by hand or with a hand-held net during spawning events in Dams 1 and 2 ( $P$. adspersus did not favour Dam 3). Animals were each implanted off-site with a radiotransmitter by a veterinary surgeon, monitored overnight, and released the next day at their capture sites. The transmitters and surgical protocol are described in Yetman \& Ferguson (in press).

Tracking was conducted between $06 \mathrm{~h} 00$ and $18 \mathrm{~h} 00$ on average twice per week, with additional surveys undertaken in response to rainfall events. A four-element Yagi antenna and AVM LA12 receiver (AVM Instruments, Champagne, Illinois) were used to detect radio-tagged frogs. Between three and 16 animals were tracked on a day. When a frog was 
located, we recorded its geographic coordinates (with a global positioning system, accurate to $4 \mathrm{~m}$ ), and the date, time, and behaviour observations. An animal's behaviour was classified as: buried (inside an open or closed burrow); present at a spawning event (regardless of whether an animal mated); guarding offspring (resting $<1 \mathrm{~m}$ from or aggressively defending eggs or tadpoles); resting at water (when an animal was found in or $<1 \mathrm{~m}$ from a dam or other inundated depression, and spawning or parental care of offspring was not observed); or resting on land (resting aboveground $>1 \mathrm{~m}$ from water, usually under vegetation). Data on the diurnal activity of radio-tracked animals were obtained for 129 days during Summers 1, 2, and 3.

Evidence of nocturnal frog activity.- -No nocturnal radio-tracking was performed because the area was considered unsafe at night. However, in Summer 3 we deduced the nocturnal emergence of animals from their burrows when the radio-tracked location of individuals changed overnight, or when a small stone placed on the plug sealing an animal's burrow had disappeared or been displaced off the plug between consecutive days of tracking. Pearson (1955) used chalk dust for the same purpose, but in our study stones were used as less conspicuous markers to prevent animals from being harvested for human consumption (Du Preez \& Cook 2004). Data on the nocturnal activity of radio-tracked animals were obtained for 31 nights in Summer 3.

Monitoring of spawning.-All aspects of breeding by P. adspersus take place at the edge of ephemeral wetlands where the water is most shallow and warm, and thus favourable for tadpole development (Cook 1996). We therefore inspected the edge of the seasonal dams 
on foot, usually every day that animals with radio-transmitters were tracked in Summers 13, and after rainfall events of $20 \mathrm{~mm}$ or more rain at the study site in Summers 4-5. Evidence of spawning by P. adspersus included observation of calling, fighting and/or mating adults, eggs, tadpoles, and/or newly-metamorphosed froglets - which were clearly visible at the water's edge and are highly diagnostic (Du Preez \& Carruthers 2009).

When a spawning event was observed, males at Dams 1-3 were counted in groups of approximately 10 individuals, if possible at different times of the day for each day that adults were seen calling, fighting and/or mating. Thus the largest count of males, and the duration of each observed spawning event was determined. Females were not counted because their smaller size and inconspicuous behaviour (Channing et al. 1994; Cook 1996) made them difficult to detect.

When eggs, tadpoles or newly-metamorphosed froglets were found without spawning having been observed, we estimated the date of spawning from the development of offspring (Gosner 1960; Van Wyk et al. 1992; Haas 1999) and measurements of daily rainfall from Diepsloot Nature Reserve. Hence, for Summers 2-5, we estimated the annual number of spawning events as the sum of all spawning events that were observed or revealed by eggs, tadpoles or froglets. The total number of spawning events in Summer 1 could not be determined since the study site was found in late mid-summer (January 2004).

Meteorological data.-For periods when P. adspersus spawned at the study site, we obtained measurements of daily rainfall from a local resident who lived $<100 \mathrm{~m}$ from the 
dams. These data were supplemented with rainfall measurements taken at $07 \mathrm{~h} 00$ daily in gauges at five different localities in Diepsloot Nature Reserve, which lies $\sim 6 \mathrm{~km}$ west of the study site $\left(25^{\circ} 55^{\prime} 36.35^{\prime \prime} \mathrm{S}, 27^{\circ} 57^{\prime} 56.09^{\prime \prime} \mathrm{E}\right)$. We treated 1 October as the first day of season (DS), and used a lunar calendar (South African Astronomical Observatory) to determine the number of days since full moon on specific dates. Days since full moon were assigned to one of eight lunar phases, ranked from 0-4 depending on the amount of moon light (ML; Table 1, adapted from Grant et al. 2009).

We obtained daily measurements of maximum and minimum atmospheric temperature (MaxT and $\operatorname{MinT}$ in ${ }^{\circ} \mathrm{C}$ ), relative humidity $\left(\mathrm{RH}\right.$ in \%), wind speed (WS in $\mathrm{m} \mathrm{s}^{-1}$ ), and atmospheric pressure $(\mathrm{P}$ in $\mathrm{hPa}$ ) from a weather station in Irene, situated $\sim 19 \mathrm{~km}$ east of the study site $\left(25^{\circ} 54^{\prime} 36.00^{\prime \prime} \mathrm{S}, 28^{\circ} 12^{\prime} 36.00^{\prime \prime} \mathrm{E}\right)$. Missing temperature data in November and December 2005, and October 2006 were substituted with daily MaxT and MinT measurements from a weather station in Kempton Park (situated $\sim 31 \mathrm{~km}$ south-east of the study site; $\left.26^{\circ} 08^{\prime} 60.00^{\prime \prime} \mathrm{S}, 28^{\circ} 13^{\prime} 48.00^{\prime \prime} \mathrm{E}\right)$. These measurements were corrected by $0.4-3.0$ ${ }^{\circ} \mathrm{C}$ depending on the mean monthly difference in each variable between the two weather stations during Summers 1-3.

Statistical analyses.--Statistical tests were performed in Statistica 7.0 (C) StatSoft, Inc. 1984-2004 Tulsa). Animals found present at a spawning event, guarding offspring, resting at water, or resting on land during radio-tracking, were considered active by day. Nocturnal activity was deduced from overnight change in an animal's radio-tracked location, or overnight displacement of the stone placed on an animal's burrow. Mann-Whitney $U$ tests 
were performed to assess whether the sexes differed in the mean number of dates during summer that individuals were buried or active by day, and/or buried or active at night. Behavioural data were used from six males and seven females that were successfully radiotracked in the day through Summers 2 and/or 3; and three males and seven females for which data on their nocturnal activity were obtained through Summer 3. Data presented are mean \pm standard deviation.

We used generalized linear models (GLZs) to investigate animal activity, and population spawning in relation to meteorological variables. Diurnal or nocturnal animal activity was measured as the daily diurnal or nocturnal "active" (arc sine transformed) proportion of animals that were successfully radio-tracked on 129 days in Summers 1-3, or 31 days in Summer 3, respectively. Population spawning was measured as a binomial variable on 743 days in Summers 1-5. Diurnal animal activity and population spawning were examined in relation to study year, the amount of previous day's rainfall (PDR), MaxT, MinT, mean day time RH, WS, and P (measured at $08 \mathrm{~h} 00$ and $14 \mathrm{~h} 00$ ), and DS. Nocturnal animal activity was examined in relation to the amount of daily rainfall (DR), MaxT, MinT, night time RH, WS, and P (measured at 20h00), DS, and ML.

We tested the predictor variables for multicollinearity using multiple regressions, and excluded predictors with a Variance Inflation Factor $(\mathrm{VIF})>2$, and/or a Tolerance $(T)$ value $<0.5$. We therefore excluded $\mathrm{RH}(\mathrm{VIF}=3.1 ; T=0.3)$ from the models of diurnal animal activity, DS (VIF $=2.4 ; T=0.4)$, and MaxT $(\mathrm{VIF}=2.3 ; T=0.4)$ from the models of nocturnal animal activity; and RH (VIF $=3.6 ; T=0.3)$ from the models of population 
spawning. VIF and $T$ values for the remaining predictor variables in the models are shown in Table 2. We assessed the utility of models of animal activity or population spawning based on a normal or binomial distribution, and an identity or logit link function, respectively. We corrected values of Akaike's Information Criterion (AIC) that were generated in Statistica, for over-dispersion of the data in all models (QAIC), and for small sample size in the models of diurnal or nocturnal animal activity $\left(\mathrm{QAIC}_{\mathrm{c}}\right.$; Symonds \& Moussalli 2010). For model averaging we used models with a corrected AIC value that differed by $<2$ from that of the "best" model of population spawning, or diurnal or nocturnal animal activity (Symonds \& Moussalli 2010). The importance of a specific predictor was estimated as the sum of the Akaike weights $\left(\sum w_{i}\right)$ of all models of diurnal or nocturnal animal activity, or population spawning, which included that specific predictor (Symonds \& Moussalli 2010).

We used a logistic regression with binomial errors to more accurately describe the relationship between PDR and population spawning, measured on 743 days in Summers 15. The duration of spawning events, or numbers of spawning males could not be examined in relation to meteorological variables using GLZs or step-wise multiple regressions, due to a small sample size ( $n=10$ observed spawning events), multicollinearity, and skewed variable distributions. Therefore, Spearman Rank correlations were used instead. Due to a small sample size ( $n=4$ summers), a Kendall Tau correlation was performed to determine whether annual numbers of spawning events were related to total summer rainfall through Summers 2-5. This method is more sensitive to some types of dependence, and deals better with ties between variables than the Spearman method (Kendall 1938). 


\section{RESUlts}

Tracking.- Of the 30 transmitter-implanted animals, 10 males and 12 females were tracked post-release. Eight females were lost from the start, and one female died and another was lost for uncertain reasons shortly after release. The 10 males and 10 remaining females were each tracked to at least one burrow. Of these 20 animals, three females and two males were tracked for several days or weeks. Seven females and four males were tracked for a complete summer, and four males were tracked during two or three successive summers. We removed transmitters from five animals, but most animals were lost when their transmitters expired.

Male versus female activity.- - Radio-tracked males were found on significantly more days in summer at water ( $10 \pm 7$ days, range: 4-18 days, $n=6$ males tracked through Summer 2 and/or 3), than females ( $3 \pm 2$ days, range: 2-6 days, $n=7$ females tracked through Summer 3, Mann-Whitney $U=5.0, P=0.02$ ). More specifically, males were found in summer on 4 \pm 2 days at a spawning event (range: 3-6 days, $n=6$ males), $1 \pm 1$ days guarding offspring (range: 0-2 days, $n=4$ males), and $5 \pm 5$ days resting at water (range: 0 - 11 days, $n=5$ males). Females were found in summer on significantly fewer days at a spawning event (2 \pm 1 days, range: $2-3$ days, $n=7$ females, $U=6.0, P=0.03$ ), and on $1 \pm 1$ days resting at water (range: $0-3$ days, $n=2$ females, $U=8.5, P=0.07$ ). Only males were found in summer, on $2 \pm 1$ days resting on land (range: 0-4 days, $n=5$ ). In Summer 3, males were 
active on more nights ( $22 \pm 5$ nights, range: 16-26 nights, $n=3$ males) than females ( $13 \pm 5$ nights, range: 9-20 nights, $n=7$ females, $U=2.0, P=0.05$ ). Overall, males were active in the day and/or night on a greater cumulative number of dates in Summer 3 (27 \pm 10 dates, range: $17-37$ dates, $n=3$ males), than females ( $14 \pm 5$ dates, range: 9-23 dates, $n=7$ females, $U=1.5, P=0.04)$.

Activity in relation to meteorological variables. - The relative importance $\left(\Sigma w_{i}\right)$ of each predictor of diurnal or nocturnal animal activity is shown in Table 3. Model averaging involved 62 models of diurnal animal activity, and 14 models of nocturnal animal activity. The coefficient estimate $(\beta)$ and standard error (SE) obtained from model averaging, for the relationship between each predictor variable, and daily diurnal or nocturnal "active" proportions of successfully radio-tracked animals, is shown in Table 3.

PDR and DS were the first and second most important predictors in all 127 models of diurnal animal activity, and were included in $100 \%$ and $52 \%$ of the 62 "best candidate" models used for model averaging (Table 3). The coefficient estimates (Table 3) indicate that more animals were diurnally active (at water or on land) earlier in summer, and following heavier rainfall. MinT, night time WS, DR, and ML were, in descending order, the most important predictors in all 31 models of nocturnal animal activity, and were, respectively, included in $100 \%, 86 \%, 71 \%$, and $57 \%$ of the 14 "best candidate" models used for model averaging (Table 3). The coefficient estimates (Table 3) indicate that more animals were nocturnally active (i.e., moved overland, and/or foraged) around full moon, after heavy rainfall, when cooler, and less windy conditions prevailed. 
Spawning in relation to meteorological variables.-Daily rainfall in Diepsloot, and $P$. adspersus spawning at the study site in Summers 1-5, are depicted in Figures 1a-e, respectively. The logistic regression between PDR and population spawning, measured on 743 days in Summers 1-5, is shown in Fig. 1f. The coefficient estimate, SE, and $P$ value was, respectively, 0.121, 0.014, and $<0.001$ for PDR, and $-4.254,0.301$, and $<0.001$ for the regression intercept. The mean amount of rain recorded 24,48 or $72 \mathrm{~h}$ prior to 25 spawning events that were observed, or revealed by offspring, was $40 \pm 16 \mathrm{~mm}$ rain $(\mathrm{min} .=$ $20 \mathrm{~mm}), 45 \pm 20 \mathrm{~mm}(\min .=22 \mathrm{~mm})$, and $51 \pm 25 \mathrm{~mm}(\min .=22 \mathrm{~mm})$, respectively Spawning occurred most frequently, in decreasing order, during December, January, and November (Fig. 2). The mean maximum count of males at 10 observed spawning events was $162 \pm 148$ males (range: $30-500$ males), and the mean duration of 15 spawning events, of which 12 were observed and three were revealed by observation of one- or two-day old eggs, was $2 \pm 1$ days (range: 1-4 days).

The relative importance $\left(\Sigma w_{i}\right)$, coefficient estimate $(\beta)$, and standard error (SE) of each predictor of population spawning, is shown in Table 3. Model averaging was based on 64 models. PDR and DS were, respectively, the first and second most important predictors in all 743 models of population spawning, and were included in $100 \%$ and $50 \%$ of the 64 "best candidate" models used for model averaging (Table 3). The coefficient estimates (Table 3) indicate that population spawning was more likely earlier in summer, and following heavier rain. 
The Spearman Rank correlation between the duration of spawning events, or numbers of spawning males, and each of 11 different predictor variables, is shown in Table 4 . The duration of spawning events was positively correlated with ML $(P=0.05)$, and the number of males at spawning events was positively correlated with the amount of previous day's rainfall $(P=0.04)$. Annually, there were $6 \pm 1$ spawning events (range: $4-7$ spawning events, $n=4$ summers), and estimated annual numbers of spawning events during Summers 2-5 were positively correlated with total summer rainfall (Kendall $T=1.0, P=0.04$, Fig. 3).

\section{DISCUSSION}

Male versus female activity.-Pyxicephalus adspersus is a difficult species to observe. Study animals cumulatively spent a month or less active during the six-month summer period. Other burrowing anurans inhabiting mesic or arid habitats exhibit similarly brief activity. For example, eastern spadefoots (Scaphiopus holbrooki) in Gainesville, Florida (Pearson 1955), and shoemaker frogs (Neobatrachus sutor) and orange-crowned toadlets (Pseudophryne occidentalis) in Western Australia (Thompson et al. 2003) spent, respectively, ca. 29 nights, and up to four days on 9 and 17 occasions, active in summer. During their brief activity, male $P$. adspersus that were radio-tracked for more than one season, evidently caught sufficient prey to sustain their large bulk through winter. This was possible, despite the degraded habitat, because $P$. adspersus preyed on termites, which were abundant on the site (CAY pers. obs.). 
Certain activity differences between male and female $P$. adspersus might be due to their pronounced dimorphism in body size (Hayes \& Licht 1992). Females avoid being terrestrially active during the day possibly because their greater surface-to-volume ratio increases their vulnerability to desiccation (Peters 1983). Males spend a greater number of nights active in summer because they visit breeding habitat more often, and because they probably need to spend more time foraging than females to satisfy their greater absolute metabolic requirements (Branch 1976; Paukstis \& Reinbold 1984). Similarly, Ovaska (1992) claimed that females of the burrowing frog Eleutherodactylus johnstonei, moved longer distances than males overland, due to their larger size and greater energy requirements. In contrast, similar-sized $(\sim 50 \mathrm{~g})$ male and female Hoplobatrachus occipitalis in a West African savanna, exhibited no difference in their timing of migrations to breeding sites, activity and home range areas, and growth during summer (Spieler \& Linsenmair 1998).

Due to the more costly and limited production of ova relative to sperm (Van Beurden 1979; Reading 1988; Blem 1992), females of many anurans only spawn 1-3 times in a season, whereas males visit most spawning events to increase their reproductive success (e.g., Perrill \& Daniel 1983; Lomen \& Madsen 1986; Sinsch 1988; Barandun et al. 1997). P. adspersus appears to fit the same trend. If adult $P$. adspersus are present for only one day of a spawning event, females and males would, respectively, attend two (33\%) and four (67\%) of six mean spawning events per annum. Thus, assuming $P$. adspersus populations 
have an adult sex ratio of 1:1, spawning events will usually appear male-biased in this species, as observed by Cook (1996).

Human disturbance at the Diepsloot dams accounts for why at least one radio-tracked male abandoned offspring (CAY pers. obs.), and likely explains why males spent one day on average in summer guarding offspring. In contrast, 109 males at Glen Austin Pan remained with their offspring for $21 \pm 9.8$ days (Cook et al. 2001).

Activity in relation to meteorological variables.- Radio-tracked males and females, respectively, spent 40 and $67 \%$ of their diurnal summer activity attending spawning events. Therefore, as with population spawning, a greater number of animals were active in the day after heavy rain, earlier in summer. Adult $P$. adspersus visit breeding sites after heavier rain because the risk of desiccation during overland migration between their burrows and breeding sites (Sjögren-Gulve 1998; Schwarzkopf \& Alford 2002), and risk of evaporation and mortality of offspring at breeding sites (Kok et al. 1989; Cook et al. 2001) is probably reduced. Adults visit breeding sites, and spawn earlier in summer because adults may attend more spawning events per annum, adults and newly-metamorphosed froglets may accumulate larger energy reserves prior to winter, and/or the abundance of predators at breeding sites may increase over summer.

On nights with less wind, and/or increased moon light, greater proportions of animals were active because it was possibly easier to catch prey, and/or detect predators (Fitzgerald \& Bider 1974; Penman et al. 2006). The influence of the moon or wind on anuran activity has 
been considered in only a few studies. For example, Penman et al. (2006) showed that the

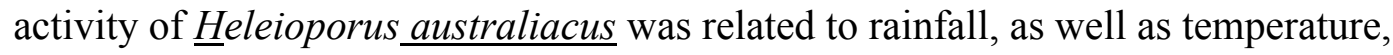
humidity, and wind strength. A meta-analysis by Grant et al. (2009) revealed that various European amphibians exhibit mass migration and spawning around full moon. Some anurans are, however, terrestrially less active during full moon possibly because the risk of detection by predators is greater, and/or important prey is less active at this time (Church 1960; Ferguson 1960; Fitzgerald \& Bider 1974; Goldberg \& Schwalbe 2004).

Spawning in relation to meteorological variables.—Pyxicephalus adspersus often spawns after ca. 50 mm or more rainfall (Grobler 1972; Cook 1996; Du Preez \& Cook 2004), but not always. At the Diepsloot site a minimum of $20 \mathrm{~mm}$ rain in $24 \mathrm{~h}$ could trigger spawning, which is equal to that reported for P. adspersus in the Free State Province (Kok et al. 1989), and for other explosive-breeding, burrowing anurans in mesic or arid habitats, e.g., S. holbrooki (Gosner \& Black 1955). Although P. adspersus spawns readily in October, population spawning appears to be most common in November, December, and January (e.g., Balinsky 1969; Kok et al. 1989; Van Wyk et al. 1992; Cook 1996). This occurred at the study site because in October the artificial dams often remained dry, and by February and March, females, at least, had probably spent most or all of their ova.

Greater moon light prolonged spawning at the study site even though $P$. adspersus spawns predominantly during day light (Balinsky 1969; Channing et al. 1994). This was possibly because moon light facilitated foraging at night around the artificial dams, which enabled males to call, fight, and/or spawn over a longer period. We noticed that spawning was also 
protracted when the weather was cool, windy, and/or overcast (CAY pers. obs.). However, due to a small sample size perhaps, no significant relationship emerged between spawning duration, and temperature, or WS. Greater numbers of males attended spawning events triggered by heavier rain because this possibly reduced the risk of desiccation during overland migration (Sjögren-Gulve 1998; Schwarzkopf \& Alford 2002), and/or improved the probability of successful reproduction, particularly for young, weak, less experienced, and/or distantly buried males.

Cook et al. (2001) reported that $P$. adspersus breeds, on average, once in four years at a particular site. In contrast, $P$. adspersus at the Diepsloot study site spawned, on average, six times each summer. The reproductive success of $P$. adspersus may differ between large, natural pans, and small, artificial dams, but many spawning events probably go unnoticed due to the unpredictable, sporadic, and brief activity of this species. Therefore, $P$. adspersus could experience greater reproductive success than might be assumed. However, cohorts of larval $P$. adspersus often suffer high mortality caused by desiccation, and predation (Cook et al. 2001), and at high larval densities there is increased competition for food (Cook 1996), cannibalism (Grobler 1972), and possibly spread of disease.

Conservation implications.-Significant differences in the temporal and spatial use of aquatic and terrestrial habitat by adult male and female $P$. adspersus have important conservation implications for the species. Males spend significantly more time at breeding sites than females, and consequently, are more vulnerable to harvesting for human consumption, which is common in Limpopo Province (Du Preez \& Cook 2004). Increased 
mortality of males at breeding sites could adversely affect tadpole survival and juvenile recruitment due to paternal care of offspring in P. adspersus (Cook et al. 2001). In contrast, females spend virtually their entire lives in burrows situated significantly farther from breeding sites than those of males (Yetman \& Ferguson in press). Females are consequently more vulnerable to encroaching land transformation (Du Preez \& Cook 2004). Pyxicephalus adspersus therefore requires effective protection of both aquatic and terrestrial habitat.

For estimation of $P$. adspersus population sizes, single counts of spawning adults are grossly inadequate because they will frequently result in severe underestimates. This was evident at our study site, where only a small proportion (10-50\%) of the highest male count (i.e., 500 males in January of Summer 3) was present at most spawning events. Adult male P. adspersus remain relatively close to their breeding site within and among years (Yetman \& Ferguson in press); therefore, frog movements are unlikely to account for the observed variation in numbers of males at spawning events. The great variation in numbers of spawning males at the Diepsloot dams obscured any trend in population size. Long term adult counts (exceeding 10 or 20 years; see Meyer et al. 2010) will, therefore, be necessary to detect real trends in the size of $P$. adspersus breeding populations. However, due to the unpredictable and brief activity of adults, it may be more practical to monitor, within certain areas, the number of aquatic sites where P. adspersus breeding occurs (Joseph et al. 2006). In this way large-scale trends can be detected for improved conservation assessment and management of P. adspersus at regional, provincial and national scales (Lindenmayer \& Likens 2010). 


\section{ACKNOWLEDGEMENTS}

We sincerely thank Jimmy, Alice and Mark Yetman, and Johan Lötter for their patient and

generous assistance with field work; Wendy Duncan for measuring local rainfall, reporting frog activity at the dams, and kindly assisting with field work; Roger Wood and Diepsloot Nature Reserve for providing additional rainfall data; the South African Weather Service for providing the bulk of the meteorological data; the Gauteng Department of Agriculture and Rural Development for issuing permits 1240 and 1296 to CAY; and Mike Perry, who introduced us to the site. The study was funded through the Endangered Wildlife Trust by Rand Merchant Bank, the Pretoria East branch of the South African Hunter's and Game Conservation Association, Arrow Bulk Marketing, Cellar Rats Wine Club, Bill Flynn and Diaz Films. We thank Michael Bates, Frank Lemckert, and three anonymous reviewers for valuable comments on previous drafts of this manuscript.

\section{REFERENCES}

BALINSKY, B.I. \& J.B. BALINSKY. 1954. On the breeding habits of the South African bullfrog, Pyxicephalus adspersus. S. Afr. J. Sci. 51: 55-58.

BALINSKY, B.I. 1969. The reproductive ecology of amphibians of the Transvaal Highveld. Zoologica Africana 4: 37-93. 
BARANDUn, J., H. ReYer \& B. ANHOLDT. 1997. Reproductive ecology of Bombina variegata: aspects of life history. Amphibia-Reptilia 18: 347-355.

Bartelt, P.E., C.R. Peterson \& R.W. Klaver. 2004. Sexual differences in the postbreeding movements and habitats selected by western toads (Bufo boreas) in southeastern Idaho. Herpetologica 60: 455-467.

BELLIS, E.D. 1965. Home range and movements of the wood frog in a northern bog. Ecol. 46: 90-98.

BLANKENHORN, H.J. 1972. Meteorological variables affecting onset and duration of calling Hyla arborea L. and Bufo calamita Laur. Oecologia 9: 223-234.

BLEM, C.R. 1992. Lipid reserves and body composition in postreproductive anurans. Comp. Biochem. Physiol., A 103: 653-656.

Both, C., I.L. KAEFER, T.G. SANTOS \& S.T.Z. CHECHIN. 2008. An austral anuran assemblage in the Neotropics: seasonal occurrence correlated with photoperiod. J. Nat. Hist. 42: 205-222.

BRANCH, W.R. 1976. Two exceptional food records for the African bullfrog, Pyxicephalus adspersus (Amphibia, Anura, Ranidae). J. Herpetol. 10: 266-268.

Bulger, J.B., J.S. SCOTT JR. \& R.B. SEYMOUR. 2003. Terrestrial activity and conservation of adult California red-legged frogs Rana aurora draytonii in coastal forests and grasslands. Biol. Conserv. 110: 85-95.

CANAVERO, A. \& M. ARIM. 2009. Clues supporting photoperiod as the main determinant of seasonal variation in amphibian activity. J. Nat. Hist. 43: 2975-2984.

Channing, A. 2001. Amphibians of central and southern Africa. Cornell Univ. Press, New York. 
Channing, A., L. Du Preez \& N. Passmore. 1994. Status, Vocalization and breeding biology of two species of African bullfrogs (Ranidae: Pyxicephalus). J. Zool. London. 234: 141-148.

CHURCH, G. 1960. The effects of seasonal and lunar changes on the breeding pattern of the edible Javanese frog, Rana cancrivora (Gravenhorst). Treubia 25: 215-233.

CoOK, C.L. 1996. Aspects of the ecology and breeding biology of the African bullfrog, Pyxicephalus adspersus. Unpubl. M.Sc. thesis, Univ. of Pretoria, Johannesburg.

CoOK, C.L., J.W.H. Ferguson \& S.R. Telford. 2001. Adaptive male parental care in the giant bullfrog, Pyxicephalus adspersus. J. Herpetol. 35: 310-315.

Duellman, W.E. \& L. Trueb. 1994. Biology of amphibians. John Hopkins Univ. Press, Maryland.

Du PreEZ, L.H. \& V. CARRUTHERS. 2009. A complete guide to the frogs of southern Africa. Random House Struik, Cape Town.

Du Preez, L.H. \& C.L. CoOK. 2004. Pyxicephalus adspersus Tschudi, 1838. Pp. 300-303. In L.R. Minter, M. Burger, J.A. HARrison, H.H. BraACK, P.J. BishoP \& D. KLOEPFER (Eds.) Atlas and Red Data Book of the frogs of South Africa, Lesotho and Swaziland. SI/MAB Series \#9. Smithsonian Institution, Washington DC.

FERGUSON, D.E. Observations on movements and behaviour of Bufo fowleri in residential areas. Herpetologica 16: 112-114.

FITZGERALD, G.J. \& J.R. BIDER. 1974. Influence of moon phase and weather factors on locomotory activity in Bufo americanus. Oikos 25: 338-340. 
GolDBERG, C.S. \& C.R. SCHWALBE. 2004. Habitat use and spatial structure of a barking frog (Eleutherodactylus augusti) population in southeastern Arizona. J. Herpetol. 38: 305-312.

GoSNER, K.L. 1960. A simplified table for staging anuran embryos and larvae with notes on identification. Herpetologica 16: 183-190.

GoSNER, K.L. \& I.H. BLACK. The effects of temperature and moisture on the reproductive cycle of Scaphiopus h. holbrooki. Am. Midl. Nat. 54: 192-203.

Grant, R.A., E.A. CHADWICK \& T. HALLIDAY. 2009. The lunar cycle: a cue for amphibian reproductive phenology? Anim. Behav. 78: 349-357.

Grobler, J.H. 1972. Observations on the amphibian Pyxicephalus adspersus Tschudi in Rhodesia. Arnoldia 6: 1-4.

HAAS, A. 1999. Larval and metamorphic skeletal development in the fast-developing frog Pyxicephalus adspersus (Anura, Ranidae). Zoomorphology 119: 23-35.

Harrison, J.A., M. Burger, L.R. Minter, A.L. DE Villiers, E.H.W. BAARd, E. SCOTt, P.J. BISHOP \& S. ELLIS. 2001. Conservation Assessment and Management Plan for Southern Africa Frogs. Final Report. IUCN/SSC Conservation Breeding Specialist Group, Minnesota.

HAYES, T. \& P. LICHT. 1992. Gonadal involvement in sexual size dimorphism in the African bullfrog (Pyxicephalus adspersus). J. Exp. Zool. 264: 130-135.

HOWARD, R.D. 1978. The evolution of mating strategies in bullfrogs, Rana catesbeiana. Evolution 32: 850-871.

IUCN (WORLD CONSERVATION UNION). 2008. The 2008 review of the IUCN Red List of threatened species. IUCN, Gland, Switzerland. 
JACOBSEN, N.H.G. 1989. A herpetological survey of the Transvaal. Unpubl. Ph.D. thesis, Univ. of Natal, Durban.

JAMESON, D.L. 1955. The population dynamics of the cliff frog, Syrrhophus marnocki. Am. Midl. Nat. 54: 342-381.

JosePh, L.N., S.A. FiELD, C. WiLCOX \& H.P. PossinghaM. 2006. Presence-absence versus abundance data for monitoring threatened species. Cons. Biol. 20: 1679-1687.

Kendall, M. 1938. A new measure of rank correlation. Biometrika 30: 81-89.

KoK, D., L.H. DU PreEZ \& A. Channing. 1989. Channel construction by the African bullfrog: another anuran parental care strategy. J. Herpetol. 23: 435-437.

LEMCKERT, F. \& T. BRASSIL. 2003. Movements and habitat use by the giant burrowing frog, Heleioporus australiacus. Amphibia-Reptilia 24: 207-211.

LINDENMAYER, D.B. \& G.E. LIKENS. 2010. The science and application of ecological monitoring. Biol. Cons. 143: 1317-1328.

LOMAN, J. \& T. MADSEN. 1986. Reproductive tactics of large and small male toads Bufo bufo. Oikos 46: 57-61.

LOVERIDGE, J.P. \& WiTHERS, P.C. 1981. Metabolism and water balance of active and cocooned African bullfrogs Pyxicephalus adspersus. Physiol. Zool. 54: 203-214.

Meyer, C.F.J., L.M.S. Aguiar, L.F. Aguirre, J. Baumgarten, F.M.Clarke, J.-F. Cosson, S.E. Villegas, J. FAhr, D. FAria, N. Furey, M. Henry, R. HodgKison, R.K.B. Jenkins, K.G. Jung, T. KingSton, T.H. KunZ, M.C. MacSwiney Gonzalez, I. Moya, J.-M. Pons, P.A. Racey, K.ReX, E.M. SAmPaio, K.E. Stoner, C.C. Voigt, D. Von Staden, C.D. Weise \& E.K.V. KalKO. 2010. Long-term 
monitoring of tropical bats for anthropogenic impact assessment: Gauging the statistical power to detect population change. Biol. Cons. 143: 2797-2807.

Minter, L.R., M. Burger, J.A. HARrison, H.H. BraACK, P.J. BishoP \& D. KLOEPFER. 2004. Atlas and Red Data Book of the Frogs of South Africa, Lesotho and Swaziland. SI/MAB Series \#9, Smithsonian Institution, Washington DC.

MucinA, L., M.C. Rutherford \& L.W. POWRIE. 2005. Vegetation Map of South Africa, Lesotho and Swaziland. 1:1 000 000. South African National Biodiversity Institute, Pretoria.

OvASKA, K. 1992. Short- and long-term movements of the frog Eleutherodactylus johnstonei in Barbados, West Indies. Copeia 1992: 569-573.

PAUKSTIS, G.L. \& S.L. REINBOLD. 1984. Observations of snake-eating by captive African bullfrogs (Pyxicephalus adspersus). Br. Herpetol. Soc. J. 10: 52-53.

Pearson, P.G. 1955. Population ecology of the spadefoot toad, Scaphiopus h. holbrooki (Harlan). Ecol. Monogr. 25: 233-267.

PenMan, T.D., F.L. LeMcKeRT \& M.J. Mahony. 2006. Meteorological effects on the activity of the giant burrowing frog (Heleioporus australiacus) in south-eastern Aust. Wildl. Res. 33: 35-40.

PerRiLl, S.A. \& R.E. DANIEL. 1983. Multiple egg clutches in Hyla regilla, H. cinerea and H. gratiosa. Copeia 1983: 513-516.

Peters, R.H. 1983. The ecological implications of body size. Cambridge Univ. Press, Cambridge. 
Philips, B.L., G.P. Brown, M. GreenleEs, J.K. WeBB \& R. Shine. 2007. Rapid expansion of the cane toad (Bufo marinus) invasion front in tropical Australia. Austral Ecol. 32: $169-176$.

READING, C.J. 1988. Growth and age at sexual maturity in common toads (Bufo bufo) from two sites in Southern England. Amphibia-Reptilia 9: 277-288.

SCHWARZKOPF, L. \& R.A. ALFORD. 2002. Nomadic movement in tropical toads. Oikos 96: 492-506.

SECOR, S.M. 2005. Physiological responses to feeding, fasting and estivation for anurans. J. Exp. Biol. 208: 2595-2608.

SEeBACHER, F. \& R.A. AlforD. 1999. Movement and microhabitat use of a terrestrial amphibian (Bufo marinus) on a tropical island: seasonal variation and environmental correlates. J. Herpetol. 33: 208-214.

SinSCH, U. 1988. Temporal spacing of breeding activity in the natterjack toad, Bufo calamita. Oecologia 76: 399-407.

SJÖGREN-GulVE, P. 1998. Spatial movement patterns in frogs: Target-orientated dispersal in the pool frog, Rana lessonae. Ecoscience 5: 31-38.

SPIELER, M. \& K.E. LinSENMAIR. 1998. Migration patterns and diurnal use of shelter in a ranid frog of a West African savannah: a telemetric study. Amphibia-Reptilia 19:4364.

SyMONDS, M.R.E. \& A. MouSSALLI. 2010. A brief guide to model selection, multimodel inference and model averaging in behavioural ecology using Akaike's information criterion. Behav. Ecol. Sociobiol. Online publication date: 25-Aug-2010. 
THOMPSON G.G., S.A. THOMPSON \& J.L. FrASER. 2003. Surface activity of arid-adapted frogs. J. Royal Soc. West Aust. 86: 115-116.

VAN AARDT, W.J. 1992. Haemolysate and haemoglobin oxygen affinity of the post hibernating African bullfrog Pyxicephalus adspersus Tschudi (Anura: Ranidae). J. Afr. Zool. 106: 39-43.

VAN BEURDEN, E. 1979. Gamete development in relation to season, moisture, energy reserve, and size in the Australian water-holding frog Cyclorana platycephalus. Herpetologica 35: 370-374.

VAN GELDER, J.J., H.M.J. AARTS \& H.W.M. StAAL. 1986. Routes and speed of migrating toads (Bufo bufo L.): a telemetric study. Herpetol. J. 1: 111-114.

VAN WYK, J.C.P., D.J. KOK \& L.H. DU PREEZ. 1992. Growth and behaviour of tadpoles and juveniles of the African bullfrog Pyxicephalus adspersus Tschudi, 1838. J. Herpetol. Assoc. Afr. 40: 56.

YeTMAN, C.A. \& J.W.H. FERGUSON (in press). Conservation implications of spatial habitat use by adult Giant Bullfrogs (Pyxicephalus adspersus). J. Herpetol. 
Table 1. Assignment of days since full moon (DFM) to one of eight lunar phases, ranked from 0-4 depending on the amount of moon light (adapted from Grant et al. 2009).

\begin{tabular}{|c|c|c|c|c|c|c|c|c|}
\hline & Full & Waning & $3^{\text {rd }}$ & Waning & New & Waxing & $1 \mathrm{st}$ & Waxing \\
\hline & moon & gibbous & quarter & crescent & moon & crescent & quarter & gibbous \\
\hline Lunar & 1 & 2 & 3 & 4 & 5 & 6 & 7 & 8 \\
\hline \multirow[t]{2}{*}{ DFM } & 28,29 , & 2,3 & 6,7 & 9,10 & 13,14 , & 17,18 & 21,22 , & 24,25 \\
\hline & 0,1 & 4,5 & 8 & 11,12 & 15,16 & 19,20 & 23 & 26,27 \\
\hline Rank & 4 & 3 & 2 & 1 & 0 & 1 & 2 & 3 \\
\hline
\end{tabular}


Table 2. Variance Inflation Factor (VIF) and Tolerance $(T)$ values for predictor variables used in generalized linear models of the diurnal, nocturnal, or spawning activity of Pyxicephalus adspersus at the Diepsloot study site. The values were obtained from multiple regressions performed after certain variables with a VIF $>2$ and/or $T<0.5$, were excluded (excl.) to reduce multicollinearity.

\begin{tabular}{|c|c|c|c|c|c|c|}
\hline & \multicolumn{2}{|c|}{ Diurnal activity } & \multicolumn{2}{|c|}{ Nocturnal activity } & \multicolumn{2}{|c|}{ Spawning } \\
\hline & VIF & $T$ & VIF & $T$ & VIF & $T$ \\
\hline Study year & 1.2 & 0.8 & - & - & 1.0 & 1.0 \\
\hline Day of season & 1.4 & 0.7 & excl. & excl. & 1.2 & 0.8 \\
\hline Previous day's rain & 1.3 & 0.8 & - & - & 1.2 & 0.8 \\
\hline Daily rain & - & - & 1.2 & 0.8 & - & - \\
\hline Max. temperature & 1.3 & 0.8 & excl. & excl. & 1.5 & 0.7 \\
\hline Min. temperature & 1.3 & 0.8 & 1.7 & 0.6 & 1.4 & 0.7 \\
\hline Wind speed & 1.1 & 0.9 & 1.1 & 0.9 & 1.2 & 0.9 \\
\hline Relative humidity & excl. & excl. & 1.4 & 0.7 & excl. & excl. \\
\hline Atmospheric pressure & 1.1 & 0.9 & 1.5 & 0.7 & 1.2 & 0.8 \\
\hline Moon light & - & - & 1.2 & 0.8 & 1.0 & 1.0 \\
\hline
\end{tabular}


Table 3. Percent $(\%)$ inclusion, relative importance $\left(\Sigma w_{i}\right)$, coefficient estimate $(\beta)$, and standard error (SE) of predictor variables used in generalized linear models of the diurnal, nocturnal, or spawning activity of Pyxicephalus adspersus at the Diepsloot study site. Percent inclusion pertains to the 62, 14, or 64 "best" models of diurnal, nocturnal, or spawning activity used for model averaging. $\Sigma w_{i}$ represents the sum of the Akaike weights of every diurnal, nocturnal, or spawning activity model (max. $n=127,31$, or 743 models, respectively) that involved a specific predictor.

\begin{tabular}{|c|c|c|c|c|c|c|c|c|c|c|c|c|}
\hline & \multicolumn{4}{|c|}{ Diurnal animal activity } & \multicolumn{4}{|c|}{ Nocturnal animal activity } & \multicolumn{4}{|c|}{ Population spawning } \\
\hline & $\%$ & $\Sigma w_{i}$ & $\beta$ & $\mathrm{SE}$ & $\%$ & $\Sigma w_{i}$ & $\beta$ & $\mathrm{SE}$ & $\%$ & $\Sigma w_{i}$ & $\beta$ & $\mathrm{SE}$ \\
\hline Intercept & - & - & 0.672 & 0.003 & - & - & 3.687 & 0.078 & - & - & 54.446 & 0.122 \\
\hline Study year & 48 & 0.46 & -0.012 & $4 \times 10^{-5}$ & - & - & - & - & 50 & 0.49 & -0.056 & $2 \times 10^{-4}$ \\
\hline Day of season & 52 & 0.58 & -0.001 & $2 \times 10^{-6}$ & - & - & - & - & 50 & 0.60 & -0.012 & $2 \times 10^{-5}$ \\
\hline Previous day's rain & 100 & 0.87 & 0.009 & $5 \times 10^{-6}$ & - & - & - & - & 100 & 0.93 & 0.122 & $6 \times 10^{-5}$ \\
\hline Daily rain & - & - & - & - & 71 & 0.63 & 0.006 & $9 \times 10^{-5}$ & - & - & - & - \\
\hline Max. temperature & 50 & 0.51 & -0.005 & $1 \times 10^{-5}$ & - & - & - & - & 50 & 0.50 & -0.007 & $7 \times 10^{-5}$ \\
\hline Min. temperature & 50 & 0.54 & -0.016 & $3 \times 10^{-5}$ & 100 & 0.76 & -0.061 & $5 \times 10^{-4}$ & 50 & 0.50 & 0.054 & $2 \times 10^{-4}$ \\
\hline Wind speed & 48 & 0.45 & $3 \times 10^{-5}$ & $7 \times 10^{-6}$ & 86 & 0.63 & -0.061 & $7 \times 10^{-4}$ & 50 & 0.49 & -0.014 & $9 \times 10^{-5}$ \\
\hline Relative humidity & - & - & - & - & 43 & 0.47 & $7 \times 10^{-4}$ & $2 \times 10^{-5}$ & - & - & - & - \\
\hline Atmospheric pressure & 48 & 0.45 & $-4 \times 10^{-5}$ & $3 \times 10^{-6}$ & 36 & 0.47 & -0.003 & $9 \times 10^{-5}$ & 50 & 0.51 & -0.068 & $1 \times 10^{-4}$ \\
\hline Moon light & - & - & - & - & 57 & 0.54 & 0.043 & $9 \times 10^{-4}$ & - & - & - & - \\
\hline
\end{tabular}


Table 4. Spearman Rank correlation between the duration of, or maximum number of males counted at, 10 observed Pyxicephalus adspersus spawning events, and various meteorological variables in Diepsloot. Not significant $=$ n.s., $* P<0.05$.

Spawning duration Max. no. of males

\begin{tabular}{|c|c|c|c|c|}
\hline & $r_{s}$ & $P$ & $r_{s}$ & $P$ \\
\hline Study year & -0.52 & n.s. & 0.12 & n.s. \\
\hline Day of season ${ }^{1}$ & -0.10 & n.s. & 0.19 & n.s. \\
\hline Previous day's rain ${ }^{1}$ & 0.03 & n.s. & 0.65 & $*$ \\
\hline Total rain ${ }^{2}$ & 0.43 & n.s. & -0.11 & n.s. \\
\hline Max. temperature ${ }^{3}$ & 0.02 & n.s. & -0.18 & n.s. \\
\hline Min. temperature ${ }^{3}$ & 0.04 & n.s. & 0.04 & n.s. \\
\hline Wind speed ${ }^{3}$ & 0.28 & n.s. & 0.21 & n.s. \\
\hline Relative humidity ${ }^{3}$ & -0.27 & n.s. & -0.02 & n.s. \\
\hline Atmospheric pressure ${ }^{3}$ & -0.08 & n.s. & 0.41 & n.s. \\
\hline Moon light ${ }^{1}$ & 0.64 & * & 0.06 & n.s. \\
\hline Max. no. of males ${ }^{2}$ & 0.34 & n.s. & - & - \\
\hline Duration of spawning & - & - & 0.34 & n.s. \\
\hline
\end{tabular}

${ }^{\mathrm{T}}$ For the first day of spawning.

${ }^{2}$ Over the full duration of spawning.

${ }^{3}$ Mean of daily values during spawning. 
A Summer $1(2003 / 2004)$

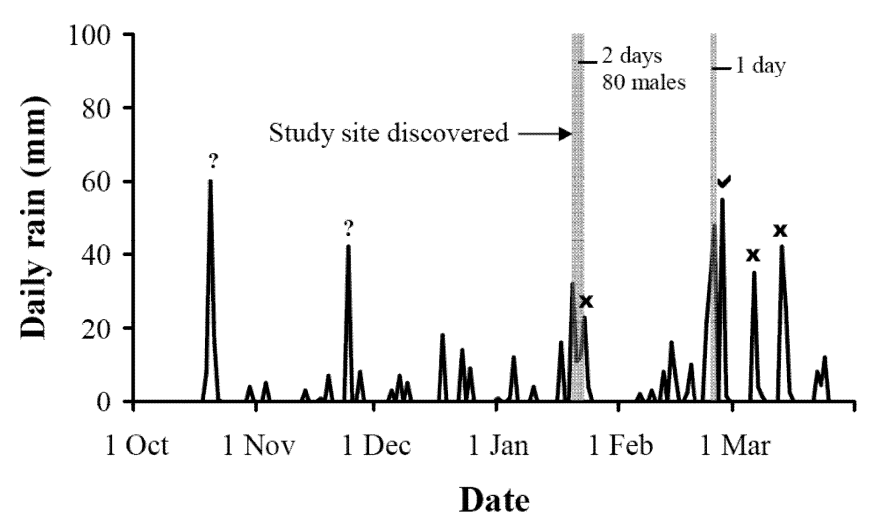

B Summer $2(\mathbf{2 0 0 4 / 2 0 0 5 )}$

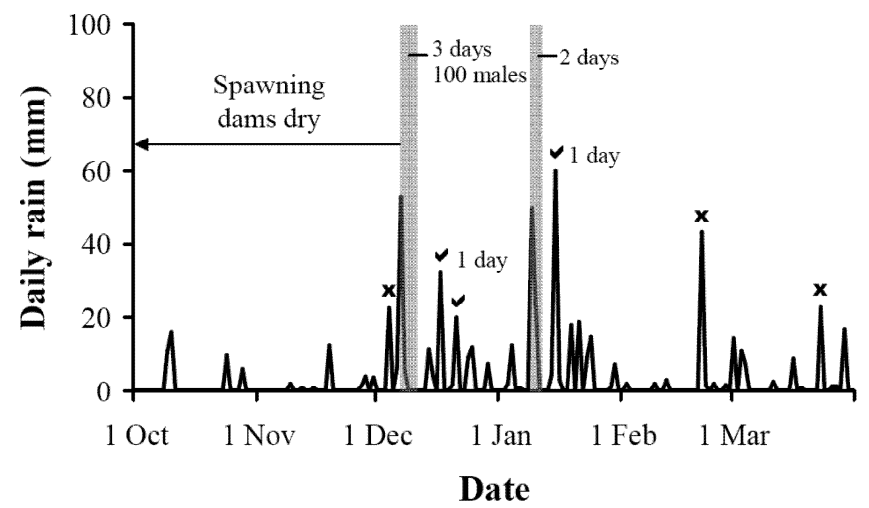

C Summer $3(2005 / 2006)$

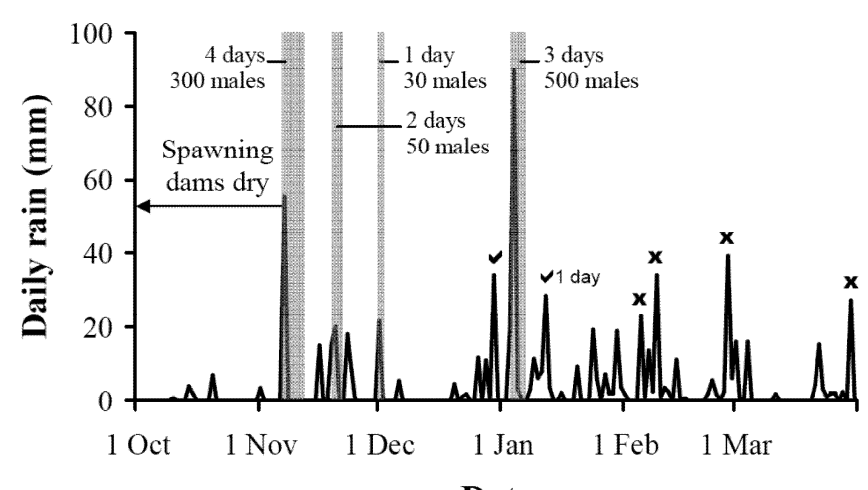

Date

\section{Summer $4(2006 / 2007)$}

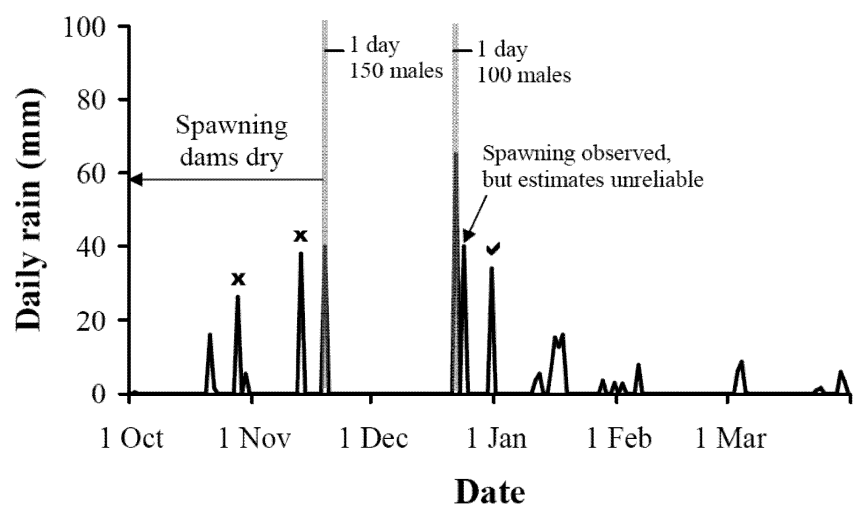

E Summer $5(2007 / 2008)$

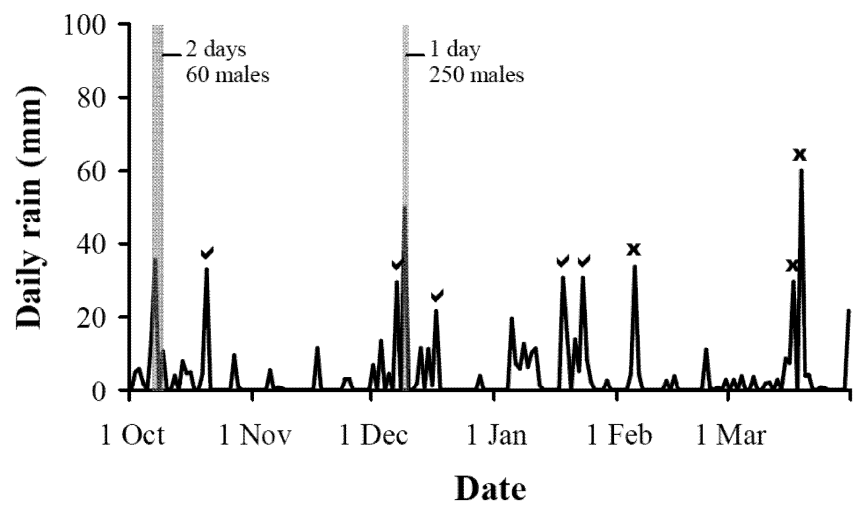

F Logistic regression

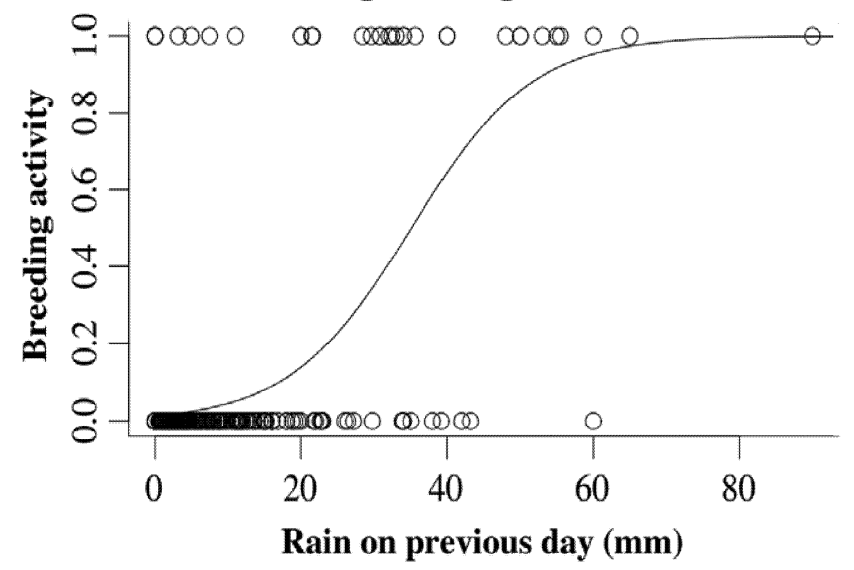


Figure 1. Daily rainfall in Diepsloot, Gauteng Province, South Africa, and known Pyxicephalus adspersus spawning activity at the study site during Summers 1-5, shown in A-E, respectively. Spawning events represented by vertical bars were observed. Those indicated by $\checkmark$ were revealed by the presence of eggs, tadpoles, and/or froglets. $\mathbf{X}$ indicates when spawning did not occur after heavy rain. (F) Logistic regression between the amount of previous day's rainfall, and $P$. adspersus spawning at the site, measured on 743 days in Summers 1-5. 


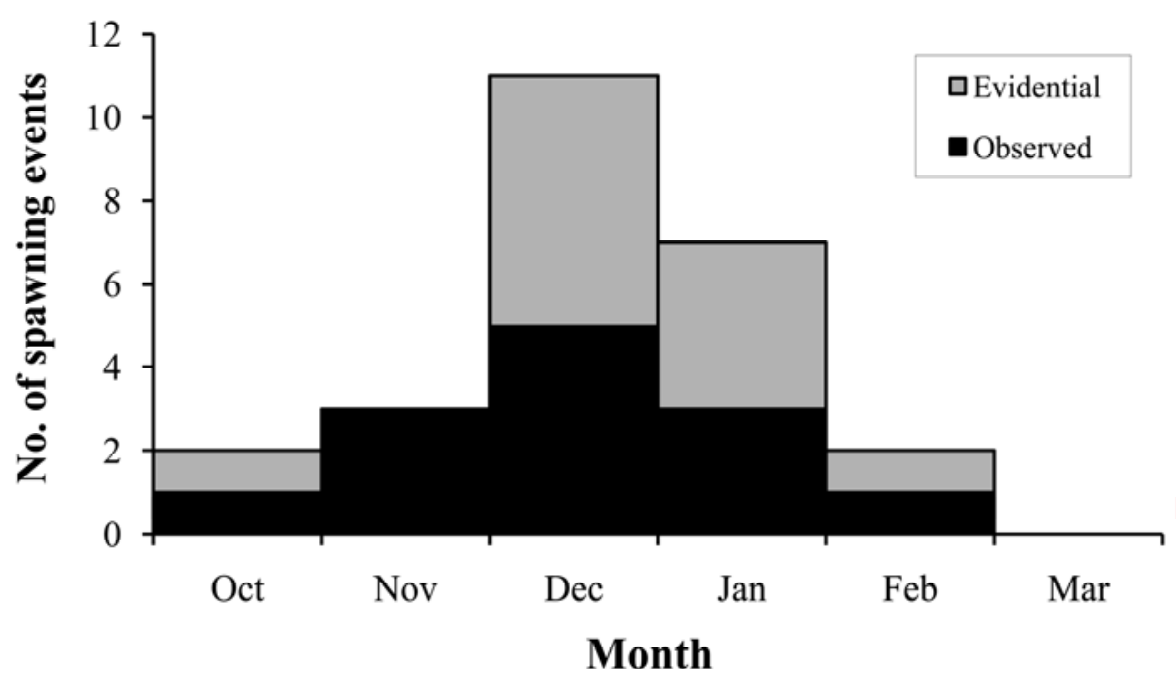

Figure 2. The number of recorded Pyxicephalus adspersus spawning events at the Diepsloot study site in different months during Summers 15. Thirteen spawning events were observed, and 12 were revealed by the presence of eggs, tadpoles and/or froglets. 


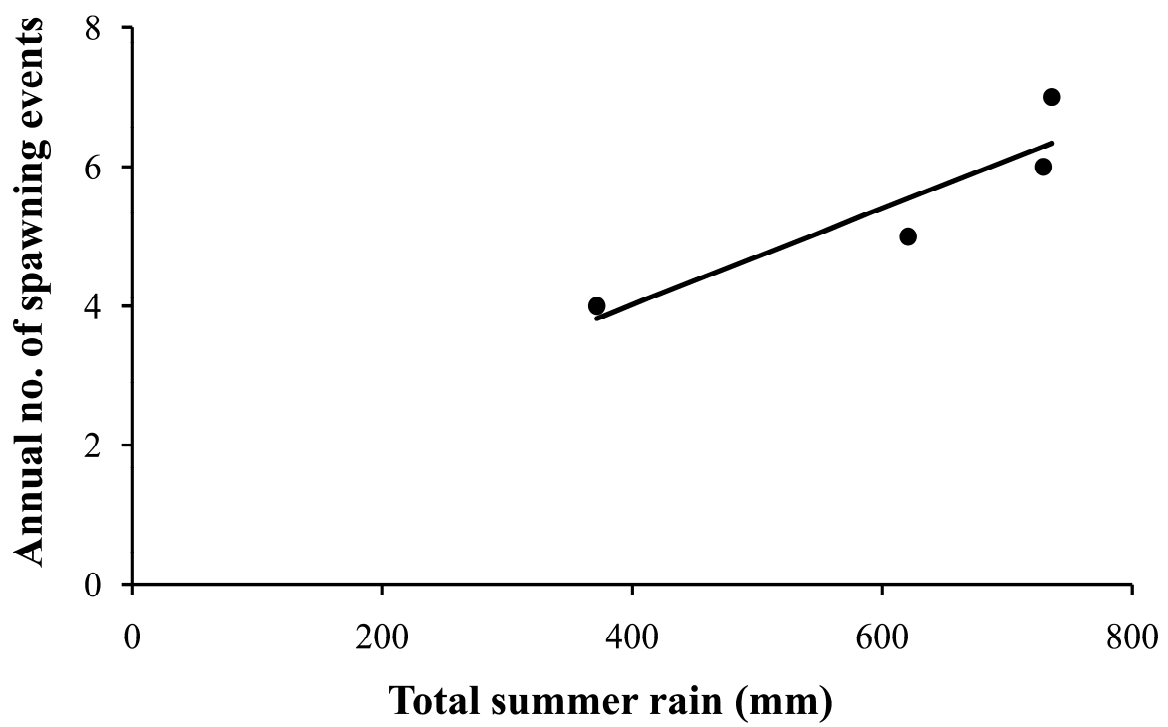

Figure 3. Kendall Tau correlation between total summer rainfall, and annual estimated numbers of Pyxicephalus adspersus spawning events during four summers at the Diepsloot study site. 